ISSN: 2277-3754

ISO 9001:2008 Certified

International Journal of Engineering and Innovative Technology (IJEIT)

Volume 10, Issue 11, May 2021

\title{
Train Wheel Force Analysis by Dynamic Analysis of High-speed Train Bridge
}

\author{
Soontaek $\mathrm{Oh}^{1}$, Dongjun Lee ${ }^{1}$, Byeongjun Jeong ${ }^{1}$, Jaeyoung Park ${ }^{1}$, Dajeong Moon ${ }^{2}$ \\ ${ }^{1}$ Seoul National University of Science and Technology, Korea
}

\begin{abstract}
A dynamic numerical analysis of the wheel forces of a Korea Train express (KTX) vehicle is conducted to investigate the traffic safety of railway bridge. It is carried out to solve the structural responses which is especially focused on either the dynamic amplification factor (DAF; vertical deflections, stresses, moments, and accelerations) of the bridge or the differences of wheel forces $(\mathrm{DWF})$ and three directions rotations of the train while travelling between on the ground and on the pre-stressed concrete (PSC) box bridge with an analysed range of running speeds from $100 \mathrm{~km} / \mathrm{h}$ to $600 \mathrm{~km} / \mathrm{h}$ by $10 \mathrm{~km} / \mathrm{h}$ increments. The numerical finite element method (FEM) with fourth order Runge-Kutta method is used to analyse the traffic safety of the bridge considering wheel-track forces between a 38 degree-of -freedom vehicle model and a track irregularity generated by the power spectral density (PSD) function. It will be proposed as indies of evaluation method ( $D A F, D W F$, and $K T X$ rotations) are recommended as the enforced traffic safety of the existing PSC box bridges due to the increasing speed of next generation KTX.
\end{abstract}

Index Terms-DAF, DWF, KTX PSC bridge, Traffic Safety, Train wheel forces.

\section{INTRODUCTION}

High-speed trains can induce implicated deflections in railway bridges, especially in simply supported ones. Additionally, the operating speeds as well as developing higher speeds of next-generation trains are evaluated enough to find out resonance conditions which have been represented some of the most demanding scenarios from the viewpoint of either infrastructure maintenances or structural design. It is of great interest to produce numerical models capable to predict accurately the amplificated deflections of the existing bridge by the increasing various speeds. Therefore, it is conducted to deal with the behaviours (i.e., deflection and acceleration of PSC bridge, wheel force and rotation of KTX) considering the train-bridge interaction model with the inertia of KTX axles, as well as the effects of the suspension.

The PSC box bridge is a typical bridge type on the KTX railway system in Korea. The PSC box bridge was established as the most suitable bridge type for the high-speed railway system through trial and error at the beginning stage of the KTX. It has been reflected upon in "the study of stability and dynamic design criteria for Railway Bridge" by the Korea Railroad Research Institute, and also improved to optimise the PSC section by the "Ho-Nam high speed railway design code (2007)". The traffic safety and serviceability of Railway Bridge are determined by an accumulated experience of the KTX during the operation period in accordance with the existing codes.

Manuscript received: 22 April 2021

Manuscript received in revised form: 21 May 2021

Manuscript accepted: 7 June 2021

Manuscript Available online: 15 June 2021
This code practice is needed to concern between the high-speed train mechanics and bridge technology. In the improved numerical program for the high-speed train PSC Bridge, the dynamic structural responses can be accurately predicted by the train-bridge interaction model. The model moving of idealised train loads are integrated with KTX train, track, and bridge behaviours [1]. This led to the large number of studies using the improved numerical model by local and foreign researchers such as Park [2], Kim [3], and Sim [4].

It is successfully operating the KTX at a speed of $300 \mathrm{~km} / \mathrm{h}$ on the both Gyung-bu and Ho-nam express railway in Korea. Furthermore, it is developing higher speed electric multiple units by $430 \mathrm{~km} / \mathrm{h}$ experimental (HEMU-430X) recorded in 2013 and the next-generation maglev train on the levitating system at expecting speed by up to $600 \mathrm{~km} / \mathrm{h}$. The higher speeds of the next-generation trains induced the development of relevant technology in order to operate on the existing infrastructure. In the traffic safety and serviceability for the higher speeds, it is needed to be studied in practically and carefully concerned with a focus on intensive research to not develop only but upgrade the existing design standards.

For this study, a simply supported PSC box railway bridge with a $40 \mathrm{~m}$ span length carrying two tracks was selected as the critical condition model among the Gung-bu express railway infrastructures. Furthermore, the approach track on the ground by $170 \mathrm{~m}$ length was combined with the front of the bridge. In such a situation, wheel-track contact forces between a 38 degree-of-freedom (DOF) KTX vehicle model and a track irregularity generated PSD function are either modelling or integrating to solve the equation of motion for the train-bridge interaction system. For the 38 DOF train model, which includes three separated kinds of masses (i.e., of a train car-body, two bogies, and four axles) the integrating force between a given axle, and the irregular surface of the track on the bridge is transformed as a function of the stiffness and deformation of suspension spring assembly. It is generated the convergence responses (i.e., displacement, velocity, and acceleration of each axle) satisfying as the initial conditions for the subsequent step. With the direct integration method, the coupled equations of motion between the train and bridge are solved using the fourth order of Runge-Kutta method [5]. It is solved to determine the magnitude of interacting forces at the end of each time interval with the speed range up to $600 \mathrm{~km} / \mathrm{h}$ by $10 \mathrm{~km} / \mathrm{h}$ increment.

\section{TRAFFIC SAFETY OF THE BRIDGE}

PreStressed Concrete (PSC) box bridge selected on the Gyungbu Express railway line in Korea are modelled to 


\section{ISSN: 2277-3754 \\ ISO 9001:2008 Certified \\ International Journal of Engineering and Innovative Technology (IJEIT) \\ Volume 10, Issue 11, May 2021}

analyse considering interaction between bridge and KTX within a running speed range of up to $600 \mathrm{~km} / \mathrm{h}$. The selected bridge detailed in Fig. 1 is simply supported with the longest span length $40 \mathrm{~m}$ in the railway line which is believed as the critical condition for the stability and safety. The existing traffic safety code of the bridge, which are too conservative to have been exposed by 17 years operation experience, was designed to satisfy: deck deflection limit of under $23.5 \mathrm{~mm}$, deflection acceleration below $0.35 \mathrm{~g}$, bridge deck end rotation restrained within $0.5 \times 10^{-3}$ radian, and a vertical profile of the deck of $1.2 \mathrm{~mm}$ by $3 \mathrm{~m}$. The conservative codes have been improved since the Honam Express railway in 2011 and the Hemu-430X in 2014 but the selected PSC bridge on the Gyungbu must endure in preparation for an increase in speed.

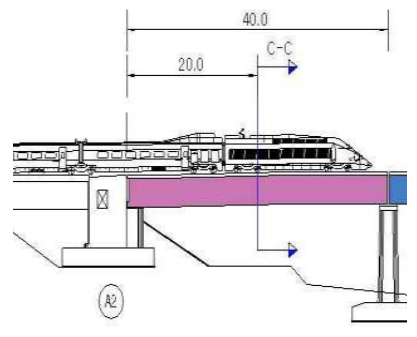

(a) Simply supported PSC Bridge

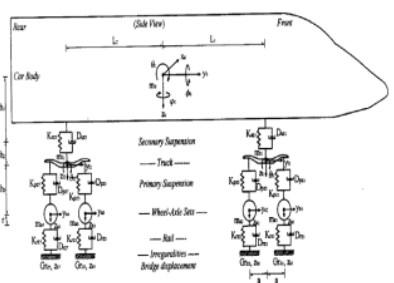

(c) 38 DOF model of KTX

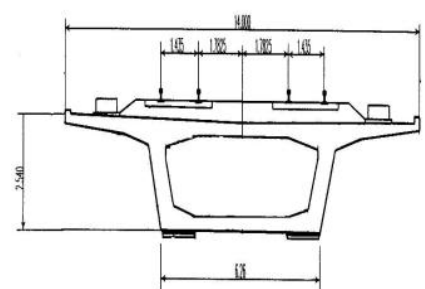

(b) PSC bridge section

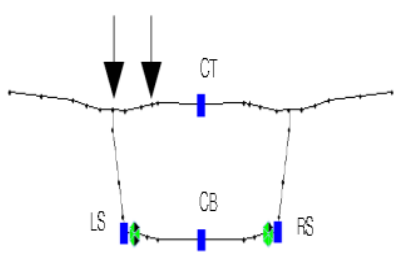

(d) Measure Points on the Model
Fig. 1. Details of the selected PSC Bridge

\section{A.Dynamic Amplification factor (DAF)}

The DAF calculated as the structural increment of behaviour (i.e., stress, moment, and deflection) ratio due to a dynamic load expressed as a fraction of an equivalent static load. Unfortunately, there is always a certain amount of ambiguity in how the increment is calculated. The DAFm considered both negative and positive behaviours is needed to clarify the actual critical condition [6]. These two factors are not equivalent shown in Fig. 2 and represented in the regression analysed Eq. (1) as a statistical model with $\mathrm{R}^{2}$ equal to $92.05 \%$ :

$\mathrm{DAFm}=-5.20 \times 10^{-8} x^{3}+3.12 \times 10^{-5} x^{2}+0.0009 \quad x+0.886$ (1)

Where $x$ is a KTX speed on the bridge $(\mathrm{km} / \mathrm{h})$ DAFm is dynamic amplification factor modified

A possible critical speed point of the graph is how much the obvious increment can affect the reliability of the results. With this procedure, the peak increment based on the Eq. (1) is calculated at the speed $430 \mathrm{~km} / \mathrm{h}$ within the analysed range.

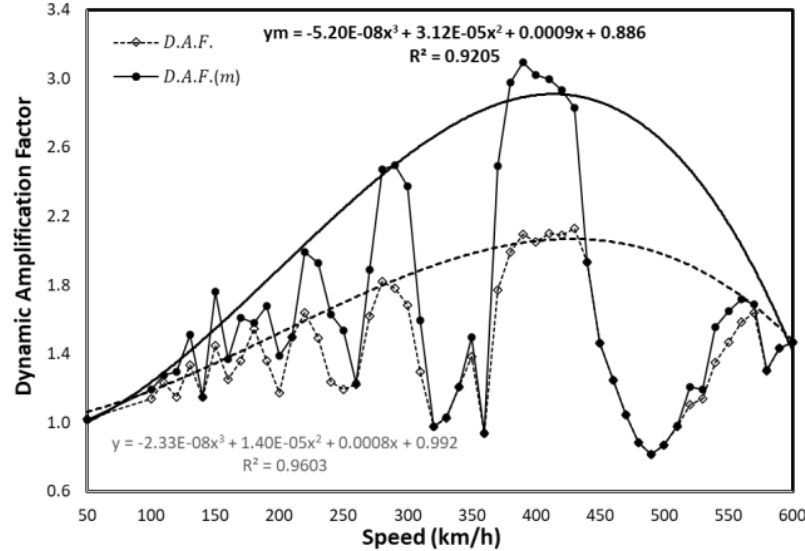

Fig. 2. DAFm of PSC Box Bridge

\section{B. Dynamic Amplification factor (DAF) of the Bridge}

The maximum deflection by $3.82 \mathrm{~mm}$ occurred at the LS measure point located at the center of the span due to simply supported bridge subjected static KTX load. The DAF influenced lines at the point LS with 12 typical running speeds present in Fig. 3 based on the response analyzed by equivalent static load.

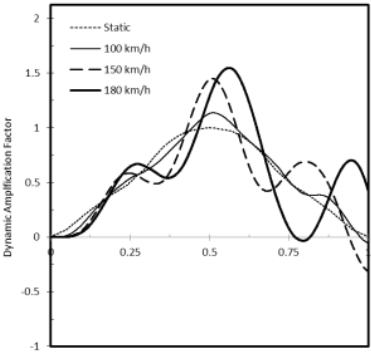

(a) under $200 \mathrm{~km} / \mathrm{h}$

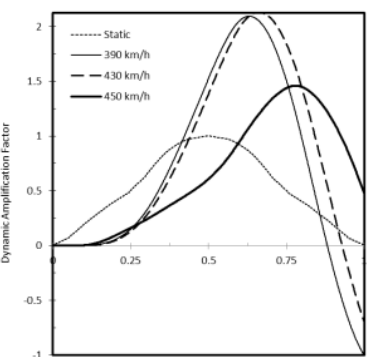

(c) under $450 \mathrm{~km} / \mathrm{h}$

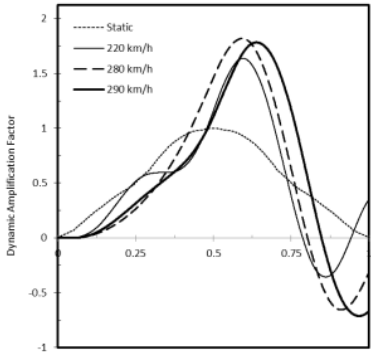

(b) under $300 \mathrm{~km} / \mathrm{h}$

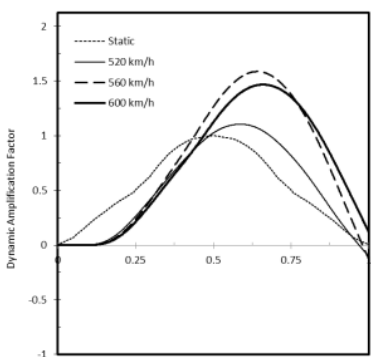

(d) under $600 \mathrm{~km} / \mathrm{h}$
Fig. 3 DAF of the PSC Bridge

The analysed range can be a separated undergoing speed range and an increasing possible speed range as well as clearly catalogued as four operating train speeds in Korea: 1) under $200 \mathrm{~km} / \mathrm{h}$ for GTX, 2) $300 \mathrm{~km} / \mathrm{h}$ for KTX, 3) $450 \mathrm{~km} / \mathrm{h}$ for HEMU and 4) $600 \mathrm{~km} / \mathrm{h}$ for next generation train.

In the first speed range shown in Fig. 3(a), the amplified deck deflections (DAF 1.45 at $150 \mathrm{~km} / \mathrm{h}$ and 1.55 at 180 $\mathrm{km} / \mathrm{h}$ ) are detected for GTX speed range, while the identical responses between static and dynamic analysis occur for normal train speed under $100 \mathrm{~km} / \mathrm{h}$. The maximum deck deflection taken into account both positive and negative 
ISSN: 2277-3754

\section{ISO 9001:2008 Certified \\ International Journal of Engineering and Innovative Technology (IJEIT) \\ Volume 10, Issue 11, May 2021}

response results that DAFm 1.76 should be greater than DAF 1.45 at $150 \mathrm{~km} / \mathrm{h}$. On the other hand, similar result with DAF 1.55 calculates DAFm 1.58 at $180 \mathrm{~km} / \mathrm{h}$ so that the negative response does not happen. Therefore, the maximum deck deflection in these speed range is observed $5.91 \mathrm{~mm}$ at 180 $\mathrm{km} / \mathrm{h}$ as well as $6.72 \mathrm{~mm}$ at $150 \mathrm{~km} / \mathrm{h}$ for accumulating both positive and negative response. In the second speed range shown in Fig. 3(b) for KTX speed under $300 \mathrm{~km} / \mathrm{h}$, the negative response extends explosively resulted that the highest DAFm 2.49 at $290 \mathrm{~km} / \mathrm{h}$ (i.e., the maximum deck deflection $9.52 \mathrm{~mm}$ ) is analysed. The analysed results are confirmed by the exist inspection data of train infrastructure operating in Korea.

In the third speed range shown in Fig. 3(c), the maximum amplified deck deflections (i.e., DAF 2.13 at $430 \mathrm{~km} / \mathrm{h}$ and DAFm 3.09 at $390 \mathrm{~km} / \mathrm{h}$ ) are detected for HEMU (developing stage train) speed range which is shown as similar trend response for KTX speed range. On the other hand, the decreasing amplified deflection both positive and negative response (i.e., DAF 1.59 by $6.06 \mathrm{~mm}$ at $560 \mathrm{~km} / \mathrm{h}$ ) resulted in similar responses between DAF and DAFm occurs for the next generation train speed under $600 \mathrm{~km} / \mathrm{h}$ shown in Fig. 3(d).

Table 1. Lateral slope of the bridge at typical speed

\begin{tabular}{|c|c|c|c|c|c|c|}
\hline speed & position & LS & CB & RS & slope 1 & slope 2 \\
\hline$(\mathrm{km} / \mathrm{h})$ & (\%) & $(\mathrm{mm})$ & $(\mathrm{mm})$ & $(\mathrm{mm})$ & $(0 / 00)$ & $(0 / 00)$ \\
\hline static & $50.0 \%$ & 3.82 & 3.19 & 2.56 & 0.226 & 0.225 \\
\hline 180 & $61.1 \%$ & 5.53 & 4.77 & 4.01 & 0.271 & 0.273 \\
\hline 280 & $59.2 \%$ & 6.94 & 5.87 & 4.80 & 0.384 & 0.381 \\
\hline 430 & $66.1 \%$ & 8.13 & 6.93 & 5.72 & 0.431 & 0.431 \\
\hline 600 & $65.8 \%$ & 5.60 & 4.85 & 4.09 & 0.270 & 0.272 \\
\hline
\end{tabular}

*position shown in Fig.1 (d)

The actual deck deflection considered the negative response is increasing to the maximum value by $11.82 \mathrm{~mm}$ at $390 \mathrm{~km} / \mathrm{h}$ as well as only positive deck deflection by $8.13 \mathrm{~mm}$ at $430 \mathrm{~km} / \mathrm{h}$ in this study. It is allowable value under limitation of the traffic safety of the train bridge in Korea. The only positive deck deflections at three measure points shown in Fig 1(d) located at the centre of bridge span can be indicated in Table 1. The calculated slopes between both points (length by $2.794 \mathrm{~m}$ ) are almost identical at each speed range. But the slopes at typical speed become getting steep and the peak points which happen the maximum deck deflection are delayed consequently in accordance with the amplificated DAF ratio compared with the static analysis result.

\section{Deck vertical acceleration}

The deck vertical acceleration trend of four typical speeds (i.e., 180, 280, 430, $600 \mathrm{~km} / \mathrm{h}$ highlighted before chapter) indicates with equivalent position of the PSC bridge shown in Fig. 4. The LS point located left side of PSC box at the center of the bridge span is selected as a representative measure point due to the maximum deck deflection occurs at the simply supported bridge. The maximum vertical acceleration by $1.333 \mathrm{~m} / \mathrm{sec}^{2}$ in whole analyzed range is calculated at speed $430 \mathrm{~km} / \mathrm{h}$. The optimistic whole analyzed results are satisfied the traffic safety limitation which is under $0.3 \mathrm{~g}$ means $2.940 \mathrm{~m} / \mathrm{sec}^{2}$. Moreover, these are too optimal results to surpass the traffic comport limitation which is double time of larger than the traffic safety one.

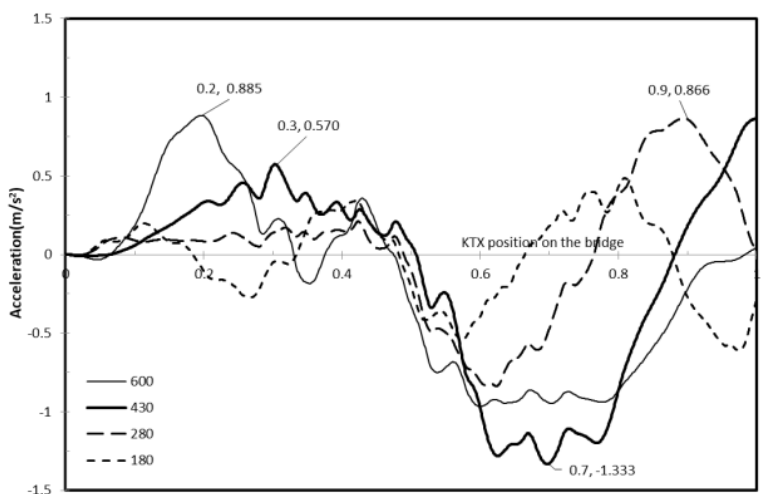

Fig. 4. Deck vertical accelerations located on the bridge

Four measure points shown in Fig. 1(d) are used to indicate deck vertical accelerations for four typical matching speeds which are represented in Fig. 5. They are not distinguished as a governed response, but in spite of selecting unmatched speeds they are precisely corresponding to the DAF responses shown in Fig. 3. For the $40 \mathrm{~m}$ bridge considered, the maximum acceleration surpasses the limit regardless of the model of the KTX train used in the analysis. The KTX power car gravity point is located midway from each of their two bogies and each of bogies has two set of wheel-axles connecting each other with suspension links either primary or secondary. They are interacted as regarded the vertical and acceleration responses. The analysed maximum deflection of the bridge is $8.13 \mathrm{~mm}$, in accordance with a permissible limit by $23.5 \mathrm{~mm}$ and the acceleration is $1.333 \mathrm{~mm} / \mathrm{sec}^{2}$, which translates to $0.136 \mathrm{~g}$ in accordance with a limit by $0.35 \mathrm{~g}$.

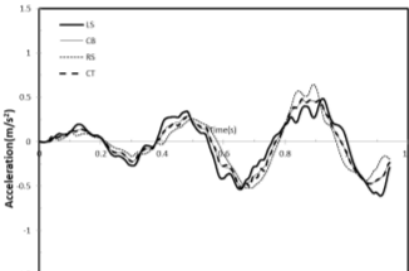

(a) $180 \mathrm{~km} / \mathrm{h}$

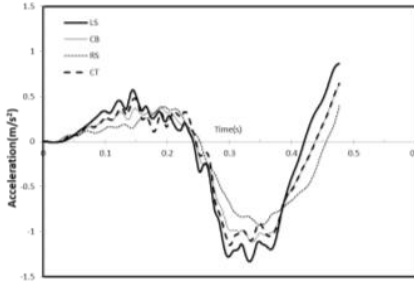

(c) $430 \mathrm{~km} / \mathrm{h}$

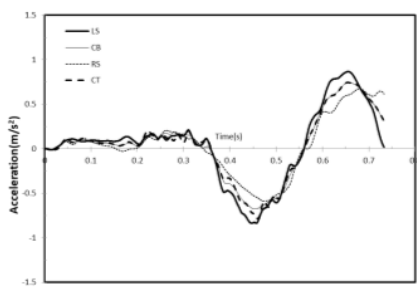

(b) $280 \mathrm{~km} / \mathrm{h}$

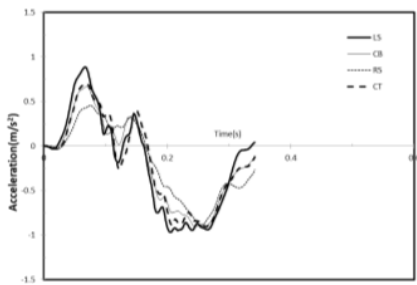

(d) $600 \mathrm{~km} / \mathrm{h}$
Fig. 5. Deck vertical acceleration with analysed time on the bridge

\section{DYNAMIC ANALYSIS OF WHEEL FORCES}

In resonance condition it is possible to find out that the oscillations of the contact forces of the rear side wheels are more critical than the corresponding to the front ones. This expectation is in fact what the KTX has the consecutive axles 


\section{ISSN: 2277-3754 \\ ISO 9001:2008 Certified \\ International Journal of Engineering and Innovative Technology (IJEIT) \\ Volume 10, Issue 11, May 2021}

with the equivalent masses. As it is apparent, the oscillation of the bridge becomes more and more intense. But the front wheels belong the first bogie are expected to create severe contact forces because non-equidistant loads and power-intensive train system are interrupted to consecutive amplification [7].

\section{A.Difference of Wheel Forces (DWF) on the Bridge}

The four front wheel forces of the KTX vehicle in vertical direction are interpreted using a 38 degree-of-freedom model consisted in the car body, two bogies, and four wheel-axles with both primary and secondary suspensions. As dynamic properties, the mass of the car body is 54.96 tonf and primary sprung mass per bogie is 2.42 tonf as well as unstrung mass per axle is 2.05 tonf. The difference of wheel forces between maximum and minimum among the four ones at the running speeds from $50 \mathrm{~km} / \mathrm{h}$ up to $600 \mathrm{~km} / \mathrm{h}$ illustrated in Fig. 6 . The average wheel force which is constant within the whole analysed range is marked. The DWF, in corresponding to the running speed, is interpreted using the third order of regression Equ. (2) as a statistical model with $\mathrm{R}^{2}$ equal to $79.3 \%$ :

$$
\begin{gathered}
\mathrm{DWF}=-4.468 \times 10^{-08} x^{3}+4.343 \times 10^{-05} x^{2}+0.002 x \\
\text { Where } x \text { is a KTX speed }(\mathrm{km} / \mathrm{h})
\end{gathered}
$$

The trend of the DWF is not only similar that of the DAF, but the peak value of DWF is also observed to be increasing within the analysed range. The DWF on the bridge exceeds the average DWF by 2.65 tonf at the running speed by 250 $\mathrm{km} / \mathrm{h}$ and keep going to increase significantly at the equivalent speed range. At the critical speed range of over $250 \mathrm{~km} / \mathrm{h}$, the DWF is greater than twice the mean value, even though the traffic operation safety criteria are satisfied as per the existing Korean national standard.

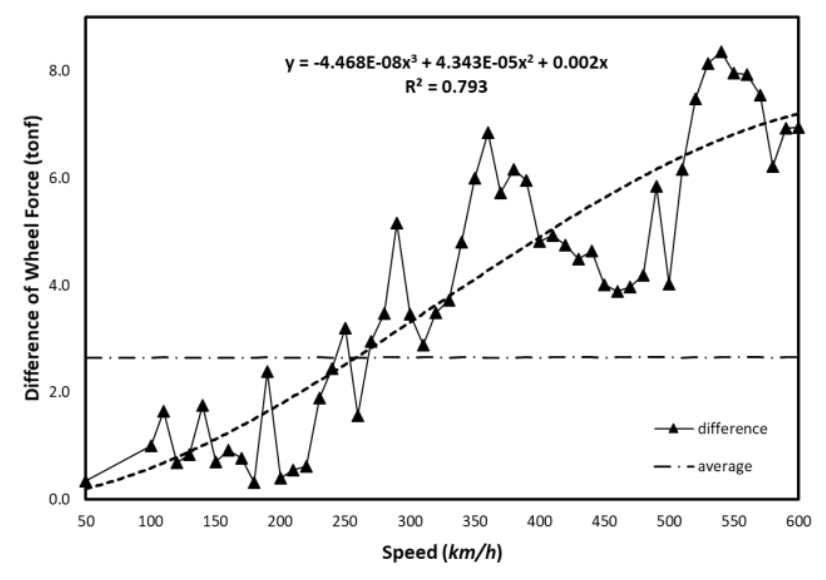

Fig. 6. DWF of PSC Box Bridge

\section{B. Wheel Forces on the Ground and the Bridge}

The maximum DWF of 6.85 tonf by $360 \mathrm{~km} / \mathrm{h}$ and 8.36 tonf by $540 \mathrm{~km} / \mathrm{h}$ are significant in its range, whatever is predicted by the proposed regression Equ. (2). The limitations in traffic operation safety at the critical speeds by both 360 and $540 \mathrm{~km} / \mathrm{h}$ are recorded as a typical value; however, all these values fall within the permissible limits successively. The wheel forces of the KTX vehicle on the bridge are constant along the PSC bridge with a mean value of 2.65 tonf, while on the ground it was observed to fluctuate between 7.36 tonf and -9.61 tonf, which is a significantly wide range. In contrast the DWF on the bridge was observed to be higher than the wheel forces, rising as high as 6.85 tonf at a speed by $360 \mathrm{~km} / \mathrm{h}$ as well as 8.36 by $540 \mathrm{~km} / \mathrm{h}$ shown in Fig. 7 .

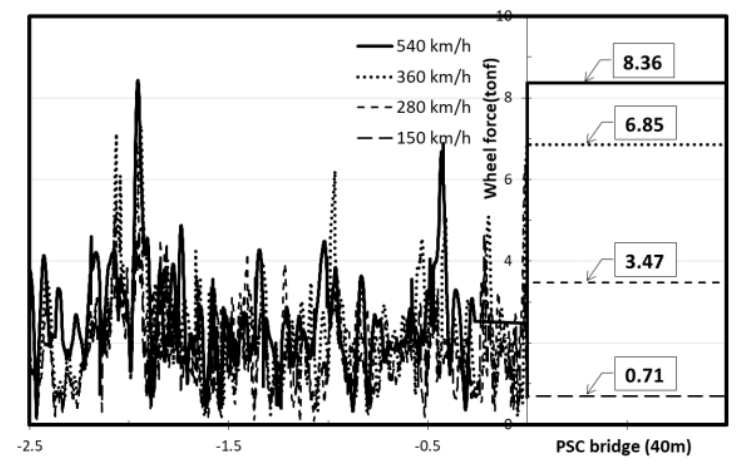

Fig. 7. Wheel forces of KTX at the speed $280 \mathrm{~km} / \mathrm{h}$ between on the ground and the bridge

All the wheel forces of the KTX front bogie on the ground show a similar trend constantly for the analysed speed range. However, the difference between both maximum and minimum wheel forces on the bridge is observed to expands significantly in equidistantly with the speed increases, as illustrated in Fig. 7. The tracks on the ground in the dynamic analysis did not allow vertical deflection (regarded invalidated flexible ballast behaviour) but consider the irregularity of rail surface against spectrum constants according to the Federal Railroad Administration track class using the PSD function. Therefore, the wheel forces of the KTX vehicle on the ground are interpreted as a typical steady trend that the fluctuation is continuous. The attenuation response of each wheel force due to the absorption of running energy that occurs simultaneously ensured that regular DWF of the wheel forces are observed.

\section{ROTATIONS OF KTX ON THE TRACKS}

Power car of KTX is modeling as 38degree of freedoms consisted three parts typically 1 car body, 2 bogies and 4 wheels. The motion equations of the power car characterized by the normal bogie system on the other hand articulated will be derived from Lagrangian formula that is considered the motions of the parts in three dimensions. All rotations (yawing, pitching, and rolling) of the KTX power car body on the track between of the ground and the bridge are discussed in here.

\section{A. Yawing rotation}

The yawing rotations of KTX at the typical running speeds are presented in Fig. 6. The swaying movements as hunting oscillation on the train track caused by coning action of wheels are attenuated gradually by the yawing damper. At high speeds comparable in size and oscillation to adhesive forces and inertial forces, the movement can be severe, destroying trail and tracks and potentially causing derailment. The problem does not occur on systems with a difference as 


\section{ISSN: 2277-3754 \\ ISO 9001:2008 Certified \\ International Journal of Engineering and Innovative Technology (IJEIT) \\ Volume 10, Issue 11, May 2021}

the action depends on both wheels of the rotation of a wheel set at the same angular rate, but differentials tend to be rare. The wheels of the power car can be impacted by hunting oscillation because the power car's wheels are fixed independently and not fastened to a pair axle are cheaper than the appropriate differential for a train's trucks.

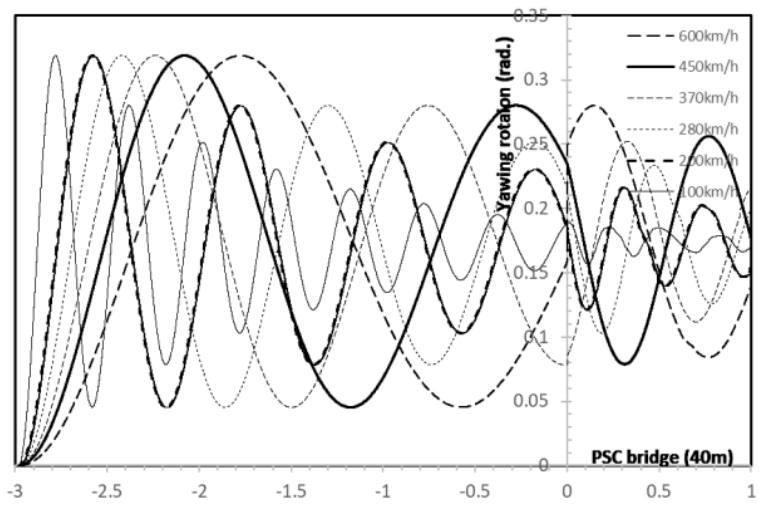

Fig. 8. Yawing rotations of KTX in the various speeds

The amount of rotation through the calculated range is started from zero almost up to 0.319 radian on the ground track, on the other hand from under 0.100 up to 0.250 radian on the bridge track. The count of oscillation within the range is observed to decrease proportionally (from 11 to 3 times) depending on the increasing speeds, while the analyzed average frequency of whole yawing rotation within the range is about $1.35(\mathrm{~Hz})$ constantly. The boldest line represents the yawing rotation at the running speed $450 \mathrm{~km} / \mathrm{h}$ which is the highest speed among the presented speeds. Nonspecial happenings passing through between on the ground and the bridge is shown through the whole observed range.

Table 2. Yawing points at the speed $460 \mathrm{~km} / \mathrm{h}$

\begin{tabular}{|l|c|c|c|c|}
\hline & time & Y. rotation & dY & mid. Point \\
\hline & (sec.) & (rad) & (rad) & (rad) \\
\hline start point & -1.330 & 0.0000003 & & \\
\hline Peak1 & -0.919 & 0.3189600 & 0.319 & 0.1595 \\
\hline Peak2 & -0.508 & 0.0452750 & 0.274 & 0.1821 \\
\hline Peak3 & -0.097 & 0.2802000 & 0.235 & 0.1627 \\
\hline Peak4 & 0.157 & 0.0789580 & 0.201 & 0.1796 \\
\hline Peak5 & 0.371 & 0.2557700 & 0.177 & 0.1674 \\
\hline end point & 0.446 & 0.2093300 & & \\
\hline
\end{tabular}

\section{*dY is difference of yawing}

Actual raw data of yawing rotation peak points at the running speed $460 \mathrm{~km} / \mathrm{h}$ is indicated in Table 1 . Within the analyzed range, interval of peak points at KTX on the ground is 0.41 second constantly on the other hand the interval peak time at KTX on the bridge is decrease to under 0.25 second. Amount of yawning rotation between the peak points are decreased from 0.319 to 0.177 dramatically while the calculated mean points between the peak points is converged from 0.182 to 0.163 .

\section{B. Pitching rotation}

The pitching rotation passing on the track point at the intersection between on the ground and bridge is an important value for the high-speed train bridge design limited as an end rotation by the traffic safety bridge code in Korea. The code oriented UIC 774-3, Eurocode 1 part 2 suggested to limit under $2.0 \times 10^{-3} / \mathrm{h}(\mathrm{rad})$ where $\mathrm{h}(\mathrm{m})$ is a length from the rail surface to the center of bearing. It is limited under $5.0 \times 10^{-4}$ (rad) for the Gyung-bu high speed train code but the limitation depending on the maximum vertical displacement of the bridge is not existing now a day due to the alternative code. The bridge end rotation led to demand for alternative to improve structural safety and serviceability should be isolated from the KTX bodies with spring and damper at the primary and secondary suspensions.

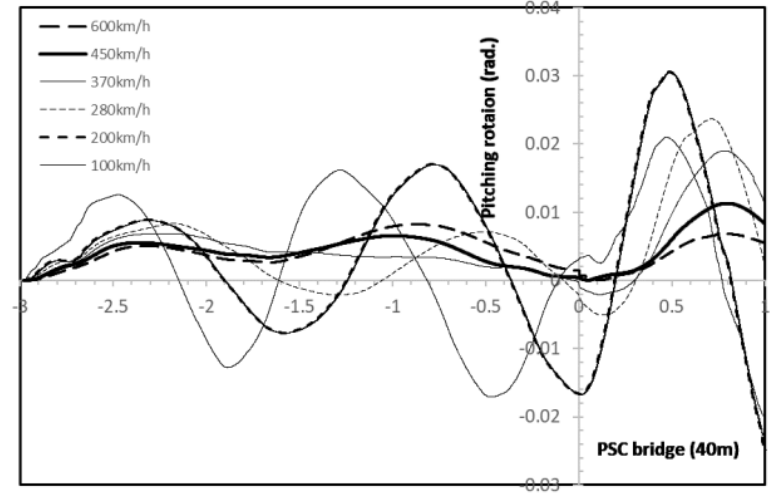

Fig. 9. Pitching rotations of KTX in the various speeds

The pitching rotations of KTX at the typical running speeds are presented in Fig. 7. The rotations crossing between positive and negative values are shown under the speed 300 $\mathrm{km} / \mathrm{h}$, otherwise the only positive value of pitching rotations is characterized over the speed including either at the PSC bridge range or the ground range. It is important that the number of values are decreasing under 0.010 radian at the whole both ranges while the three time of rotation value is indicated at the speed $200 \mathrm{~km} / \mathrm{h}$ on the bridge especially. It is good evidence that the suspension system of KTX works very well to endure the pitching rotation value stably despite the increasing vertical displacement due to increasing impact factor by high running speed.

\section{Rolling rotation}

The rolling rotational movement of KTX running on the bridge through the longitudinal direction is well known to be affected by lateral displacements of the PSC train bridge.

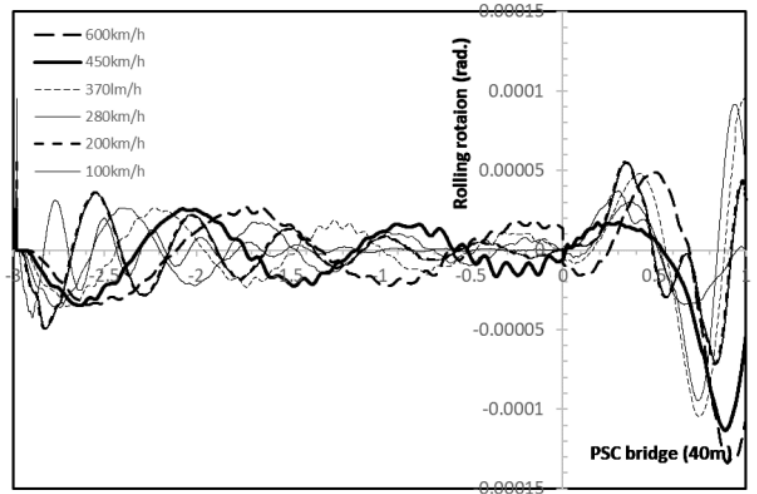

Fig. 8. Rolling rotations of KTX in the various speeds 


\section{ISSN: 2277-3754 \\ ISO 9001:2008 Certified \\ International Journal of Engineering and Innovative Technology (IJEIT) \\ Volume 10, Issue 11, May 2021}

The rolling rotations of KTX at the typical running speeds are presented in Fig. 8. The amount of rotation value is very smaller rather than either ten-thousandths of yawning or one over a hundredth pitching rotation. Even though the rotation value is relatively smaller rather than under $0.3 \times 10^{-4}(\mathrm{rad})$ at the ground range, an explosive expansion over $1.0 \times 10^{-4}(\mathrm{rad})$ is shown dramatically KTX running on the bridge with higher speed over $300 \mathrm{~km} / \mathrm{h}$. It is why the rolling rotation is affected greatly as the speed increases by the lateral displacement of the double train track PSC bridge and whatever the instrument to prevent the increasing rotation is needed.

\section{DISCUSSIONS}

A simply supported PSC box railway bridge with a $40 \mathrm{~m}$ span length carrying two tracks was selected to investigate the traffic safety for increasing speed up to $600 \mathrm{~km} / \mathrm{h}$ among the Gyung-bu express railway infrastructures using FEM modelling. Analyzed responses should discuss the following points:

1) The analysed maximum deflection of the bridge is 8.13 $\mathrm{mm}$, in accordance with a permissible limit by $23.5 \mathrm{~mm}$ and the acceleration is $1.333 \mathrm{~mm} / \mathrm{sec}^{2}$, which translates to $0.136 \mathrm{~g}$ in accordance with a limit by $0.35 \mathrm{~g}$.

2) The maximum DWF of 6.85 tonf by $360 \mathrm{~km} / \mathrm{h}$ and 8.36 tonf by $540 \mathrm{~km} / \mathrm{h}$ are significant in its range. The limitations in traffic operation safety at the critical speeds by both 360 and $540 \mathrm{~km} / \mathrm{h}$ are recorded as a typical value; however, all these values fall within the permissible limits successively.

3) Amount of yawning rotation between the peak points are decreased from 0.319 to 0.177 dramatically while the calculated mean points between the peak points is converged from 0.182 to 0.163 .

4) The numbers of pitching rotations are decreasing under 0.010 radian at the whole both ranges while the three time of rotation value is indicated at the speed $200 \mathrm{~km} / \mathrm{h}$ on the bridge especially.

5) The amount of rotation value is very smaller rather than either ten-thousandths of yawing or one over a hundredth pitching rotation. Even though the rotation value is relatively smaller rather than under $0.3 \times 10^{-4}(\mathrm{rad})$ at the ground range, an explosive expansion over $1.0 \times 10^{-4}$ (rad) is shown dramatically KTX running on the bridge with higher speed over $300 \mathrm{~km} / \mathrm{h}$.

6) The points will be proposed as Indies of evaluation method are recommended as the enforced traffic safety of the existing PSC box bridges due to the increasing speed of next generation KTX.

\section{ACKNOWLEDGMENT}

This study was supported by the Research Program funded by the Seoul National University of Science and Technology.

\section{REFERENCES}

[1] S. T. Oh, D. J. Lee, and D. J. Moon, "Numerical Analysis of Wheel Forces of a KTX Vehicle on a PSC Box
Bridge," Quest Journals, Journal of Architecture and Civil Engineering, vol. 4(1), pp. 20-27, 2019.

[2] H. S. Park, "A Study of Dynamic Analysis of Bridges using High-Speed Train model," PhD. dissertation, Yonsei University, Seoul, Korea, 1998.

[3] S. Y. Kim, "Bridge-Train Interaction Analysis of High-Speed Railway Bridges," PhD. dissertation, Seoul National University, Seoul, Korea, 2000.

[4] Y. W. Sim, "An Interface Study of Dynamic Behavior on High-Speed Train Vehicle/Track/PSC bridge," PhD. dissertation, Seoul National University of Science and Technology, Graduate School of Railroad, Seoul, Korea, 2012.

[5] S. T. Oh, Y. W. Shim, and D. J. Lee, "Dynamic Analysis of PSC Bridge for a High-Speed Railway Vehicle Using Improved 38-Degree of Freedom Model," Journal of the Korea Concrete Institute, 22(6), pp: 797-803,2010.

[6] D. J. Moon, "A study of the running safety for next generation high-speed railway bridge considering running speed," Master D. dissertation, Seoul National University of Science and Technology, Civil Engineering, Seoul, Korea, 2019.

[7] D. J. Lee and S. T. Oh, "Ultimate Axial Strength of RC Slender Walls with Openings," IJEIT, International Journal of Engineering and Innovative Technology, 7(10), pp: 13-19, 2018. 